\title{
Article \\ Effect of Childbirth Experience on Cognitive Performance and Event-Related Potential Patterns
}

\author{
Mi-Hyun Choi ${ }^{1}{ }^{\mathbb{D}}$, Jin-Ju Jung ${ }^{1}$, Je-Hyeop Lee ${ }^{1}$, Soon-Cheol Chung ${ }^{1}{ }^{\mathbb{D}}$, Hyun-Kyung Park ${ }^{2}$ and \\ Hyun-Jun Kim ${ }^{3,4, *}$
}

Citation: Choi, M.-H.; Jung, J.-J.; Lee, J.-H.; Chung, S.-C.; Park, H.-K.; Kim, H.-J. Effect of Childbirth Experience on Cognitive Performance and Event-Related Potential Patterns. Appl. Sci. 2021, 11, 3233. https:// doi.org/10.3390/app11073233

Received: 8 March 2021

Accepted: 31 March 2021

Published: 4 April 2021

Publisher's Note: MDPI stays neutral with regard to jurisdictional claims in published maps and institutional affiliations.

Copyright: (c) 2021 by the authors. Licensee MDPI, Basel, Switzerland. This article is an open access article distributed under the terms and conditions of the Creative Commons Attribution (CC BY) license (https:// creativecommons.org/licenses/by/ $4.0 /)$.
1 Biomedical Engineering, Research Institute of Biomedical Engineering, School of ICT Convergence Engineering, College of Science \& Technology, Konkuk University, Chungju 27478, Korea; mhchoi0311@gmail.com (M.-H.C.); wjd3621@kku.ac.kr (J.-J.J.); charlie63@kku.ac.kr (J.-H.L.); scchung@kku.ac.kr (S.-C.C.)

2 Department of Laboratory Medicine, Seoul Clinical Laboratories, Yongin 16954, Korea; vega5802@naver.com

3 Department of Obstetrics and Gynecology, Konkuk University School of Medicine, Chungju 27478, Korea

4 Research Institute of Medical Science, Konkuk University School of Medicine, Seoul 05029, Korea

* Correspondence: icarus@kku.ac.kr; Tel.: +82-43-840-8310

\begin{abstract}
This study aimed to compare the cognitive performance and event-related potential (ERP) patterns between females who have given birth (parous) and those who have not (nulliparous). A total of 50 female participants, including 27 who were parous (33.2 \pm 3.2 years) and 23 who were nulliparous ( $30.8 \pm 2.3$ years), were recruited. Only parous females who were $\leq 36$ months postpartum (17.7 \pm 8.1 months) were included. To compare the cognitive performance between the two groups, we presented the 3-back task (a working memory task) and compared the accuracy rate $(\%)$ and reaction time $(\mathrm{ms})$ between the groups. Electroencephalogram (EEG) signals were simultaneously recorded and the ERP patterns at $\mathrm{Fz}, \mathrm{Cz}$, and $\mathrm{Pz}$, which are highly associated with the 3-back task, were analyzed. From the ERP patterns, we extracted N100, P300, P600, P300 peak-to-peak (P300p_p), and P600 peak-to-peak (P600p_p). There were no significant between-group differences in terms of accuracy rate, reaction time, or ERP components (N100, P300, P600, P300p_p, or P600p_p) at the three sites $(\mathrm{Fz}, \mathrm{Cz}$, and $\mathrm{Pz})$. Since this study, using meaningful objective data, did not show that parity was significantly correlated with cognitive performance ability and ERP patterns, childbirth does not appear to influence cognitive decline.
\end{abstract}

Keywords: childbirth; cognitive performance; event-related potential; 3-back task; Fz; Cz; Pz

\section{Introduction}

In self-report evaluations regarding the occurrence of depression after childbirth and the negative effects of pregnancy, difficulty concentrating and short-term memory loss, among other symptoms, were reported [1,2]. Anxiety about the decline in cognitive function associated with pregnancy is thought to be due to an increase in psychological and physical stress [3]. However, scientific evidence of this phenomenon has not been clearly established. Most previous studies have suggested that these symptoms can be explained by hormonal and cognitive changes that occur during pregnancy and in the postpartum period. In other words, hormones like oxytocin, estradiol, and cortisol, which vary greatly during pregnancy and childbirth, are known to induce cognitive changes [3-12]. Although there have been various attempts to objectively observe the changes in cognitive performance in pregnant women and mothers, results have not been consistent $[1,13]$.

It has been reported that a decline in memory occurs due to the effects of pregnancy and that a decrease in gray matter volume in the hippocampal region related to memory is recovered only two to three years after childbirth [9,14]. However, no significant changes in memory have been found after pregnancy, and no consistent results have been reported $[1,8,9,14-16]$. There have also been reports of deficits in attention, changes in language expression skills, cognitive decline, and memory loss during pregnancy. It has been 
suggested that these are not objective changes caused by hormones but rather are related to sudden changes in sleep patterns (sleep time, sleep quality, insomnia, etc.) $[17,18]$ due to factors such as fetal movement and urinary frequency during pregnancy $[19,20]$. Moreover, the decline in cognitive function during pregnancy has been attributed to the increase in psychological and physical stress [3]. To date, changes in cognitive performance, hormones, brain volume, and the surrounding environment, as well as stress, have been correlated with cognitive changes during pregnancy and/or childbirth; however, it has been difficult to produce consistent results.

Therefore, to more accurately verify the correlation between pregnancy/birth and cognitive changes, further research based on biosignals, which can serve as another objective evaluation index, is required. In particular, the amplitude of the event-related potential (ERP) parameters of electroencephalogram (EEG) signals during a cognitive task can be used to clearly indicate task performance [21-35]. During the performance of working memory tasks, EEG activity appears in the midfrontal and occipital cortex regions [21,22,24-28]. Among the extractable ERP components, the amplitude of the P300 element is processed when determining whether a presented stimulus is consistent or inconsistent with a previous stimulus during trials [22] and is known to reflect the process of updating memory [29] and the allocation of surrounding resources [30,31]. In the case of language tasks, activation has been reported in the posterior region of the brain with the N400 component, which reflects semantic processing [32], and the P600 components, which reflect re-analysis processes that correct the initial syntactic analysis $[23,33]$. For spatial tasks, ERP has been clearly observed in the $\mathrm{Pz}$ domain, with alterations in the amplitudes of the components P200 and P300 [34]. In other words, the ERP appears to be associated with different components according to the type of task, which suggests that the components represent different brain activity patterns [35]. In addition, changes in amplitude among ERP components are related to cognitive behavior, so it is an objective indicator suitable for comparing more precise cognitive performance.

To better understand the effect of pregnancy on cognitive function, this study aimed to objectively show whether a decrease in cognitive performance occurs in women after childbirth. The following hypothesis was established based on previous research results suggesting that cognitive function decreases and is then recovered two to three years after childbirth. In this study, we hypothesized that there is a difference in cognitive performance between women who have given birth within the previous two to three years and women who have never given birth. If a difference is observed in cognitive performance, we hypothesize that this will be reflected in the ERP patterns (amplitude) of the brain regions involved.

Therefore, the present study aimed to compare the cognitive performance (correct answer rate, reaction time) of the two parity groups: women who have carried at least one pregnancy to viability ( $\geq 1$ para) and women who have never given birth (nullipara), using the 3-back task, a cognitive task that tests working memory. In particular, we measured ERP signals, which are strongly correlated with changes in cognitive performance, during the cognitive task to objectively compare the groups.

\section{Materials and Methods}

\subsection{Subjects}

A total of 27 parous women (aged $33.2 \pm 3.2$ years) and 23 nulliparous women (aged $30.8 \pm 2.3$ years) participated in this study. Age (between 27 and 37 years) and educational level (university graduation, bachelor's degree) were analyzed between the groups. During pregnancy, childbirth, and the postpartum period, major hormone changes take place in women, which may affect physical, emotional, and cognitive function. According to previous studies, the decrease in the volume of the hippocampus related to memory loss is restored around three years after childbirth $[9,14]$. Therefore, women who gave birth within the previous 36 months were recruited for the parous group in this study. In this group, age, delivery date (postpartum periods), delivery method (vaginal delivery, cesarean deliv- 
ery), number of fetuses (single birth, multiple births), and education level of the subjects were collected. Of the 27 subjects, 16 gave birth by cesarean section and 11 gave birth by vaginal delivery. Additionally, 2 had multiple births and the remaining 25 had single births. In addition, the average postpartum period, which was counted from the delivery date, was $17.7 \pm 8.1$ months. This study was approved by the Institutional Bioethics Committee of Konkuk University (IRB project number: 7001355-201709-HR-203) and complied with the regulations of the Helsinki Declaration. Prior to the experiment, participants were informed about the study and provided written informed consent.

\subsection{The 3-Back Task}

Given the previous findings that cognitive function changes are more apparent when memory load is increased [36], we conducted a high-difficulty 3-back task to compare more distinct differences in cognitive function between the two groups.

We presented a 3-back task using 6 letters (A-F), as shown in Figure 1a. SuperLab5 (Cedrus) was used as the stimulus presentation program. The "3-back task" refers to a case where the alphabet presented in Figure 1a is the same as the alphabet presented three tasks before, in which the participant was asked to respond by pressing the space bar button as fast as possible. Each letter stimulus was presented for $800 \mathrm{~ms}$ (task time), and a blank screen (+) was presented during the interstimulus interval (2000 $\mathrm{ms}$, rest time) (Figure 1b). A total of 100 letters were randomly presented one at a time, of which 30 were the target letter requiring the motor response. Participants performed practice trials until they fully understood the task procedure and then performed the actual test trial. After all trials were completed, we calculated the accuracy rate (\%) and reaction time (ms).

\section{Accuracy rate $(\%)=($ number of correct answers $/$ total number of questions $) \times 100$}

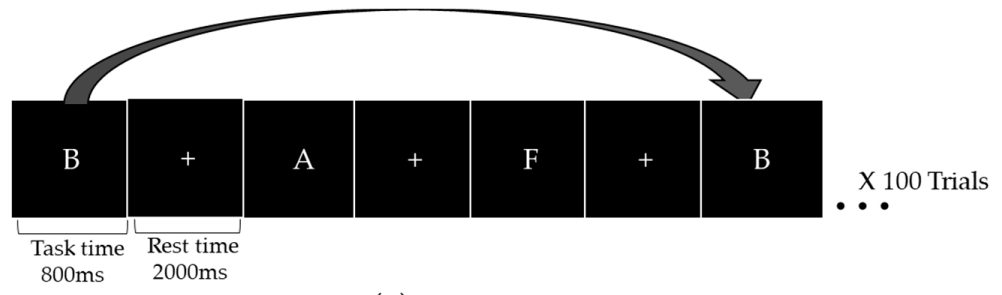

(a)

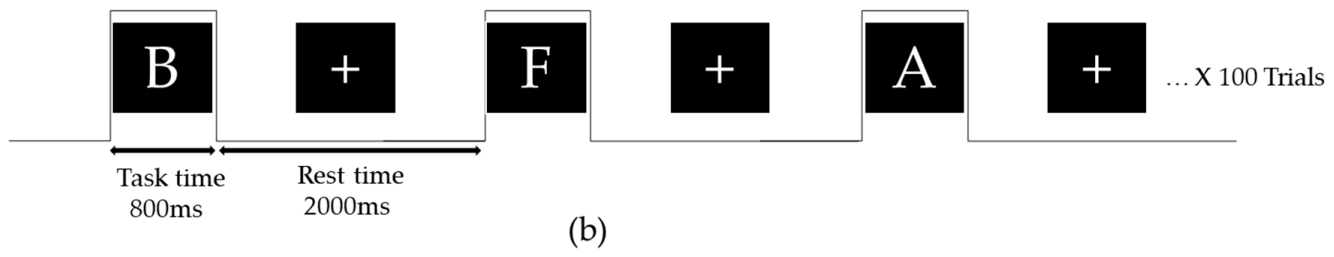

Figure 1. (a) Demonstration of the 3-back task; (b) experimental design.

\subsection{EEG Measurement and Analysis}

An electroencephalogram (EEG) was used to measure brain activity throughout the entire cognitive task session. The EEG was recorded using Enobio20 (NeuroElectrics, Barcelona, Spain) at a sampling rate of $500 \mathrm{~Hz}$. We placed electrodes at a total of 19 locations based on the 10-20 system, with the reference electrode on the right mastoid and the ground on the right earlobe (Figure 2). The wet-electrode system (The Geltrode has a $\mathrm{Ag} / \mathrm{AgCl}$ coated core with $12 \mathrm{~mm}$ diameter) was used, where the EEG signal was obtained by attaching the electrodes at the indicated sites, as shown in Figure 2. Impedance between the electrodes and the scalp was maintained below $5 \mathrm{k} \Omega$. Participants wore earphones with white noise to exclude the auditory factor, and the experiment was conducted at an independent laboratory to block external stimuli. 


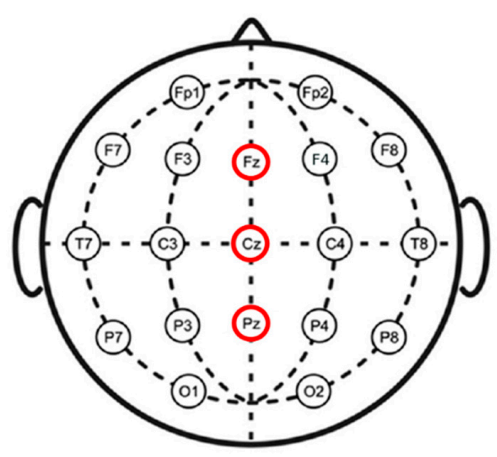

Figure 2. The 19 electrodes based on the 10-20 system.

Prior to conducting the EEG analysis, we first extracted and analyzed the trials in which the subjects selected the correct answers for the task. We analyzed the EEG data using MATLAB 2017 (Mathworks, USA). We analyzed signals recorded at Fz, Cz, and Pz, which are midline sites highly correlated with working memory tasks (3-back task) [25-28].

Bandpass filtering $(0.5-20[\mathrm{~Hz}])$ was used to remove power noise $(60 \mathrm{~Hz})$. That is, locutoff (low-edge frequency in passband $(\mathrm{Hz})$ ) and hicutoff (high-edge frequency in passband $(\mathrm{Hz})$ ) were set using the eegfiltfft function. After converting the data from timeseries data to the frequency axis using fast Fourier transform (FFT), preprocessing was performed to extract only the frequency band between 0.5 and $20 \mathrm{~Hz}$ by removing the area outside the set frequency band as 0 . We extracted epochs of the data from $200 \mathrm{~ms}$ before stimulus presentation (base time) to $1500 \mathrm{~ms}$ after stimulus presentation (onset time). In order to eliminate artifacts like eye movements, we removed trials that surpassed $40 \mathrm{uV}$ and kept the total ERP of each participant under $25 \mathrm{uV}$. A total of 100 trials were recorded for each participant, and after extracting the correct answer (23.33 trials on average), bad trials were removed ( 9.5 bad trials on average). Additionally, we averaged the EEG signals for each patient and performed baseline correction based on the signal at the base time. Finally, we analyzed the ERPs by group.

After completing the above preprocessing procedure, the N100, P300, P600, P300 peak-to-peak (P300p_p), and P600 peak-to-peak (P600p_p) were extracted from the average ERP pattern at the three sites $(\mathrm{Fz}, \mathrm{Cz}$, and $\mathrm{Pz})$ according to the following definitions: N100 was defined as the negative peak at 60-200 ms, while P300 and P600 were defined as the positive peak at $250-400 \mathrm{~ms}$ and $500-700 \mathrm{~ms}$, respectively. P300p_p was defined as the difference between P300 and N100, and P600p_p was defined as the difference between P600 and N100. Among the ERP components, the amplitude varied according to the amount of attentional resources in the attentional reservoir. Therefore, changes in amplitude are important parameters to evaluate cognitive workload [37]. In this study, the amplitude of each component (N100, P300, P600, P300p_p, and P600p_p) of the ERP pattern was extracted for each group and subject.

A multivariate analysis of covariance (MANCOVA) was conducted to examine whether there were any significant differences in the amplitudes and accuracy rates and reaction times between the two groups in terms of components extracted from the three sites between the two groups (SPSS version 25, IBM, New York, NY, USA). MANCOVA was performed after the independent $t$-test results showed a statistically significant age difference between the two groups $(p=0.004)$. Given the research findings [38] that have demonstrated the effects of age differences on cognitive performance, both the age and education level were collected from the subjects and set as covariates. Simply put, the analysis was conducted by determining the dependent variables as the amplitude of each component (N100, P300, P600, P300p_p, and P600p_p) of Fz, Cz, and Pz; the accuracy rate of the 3-back task; and the reaction time of the 3-back task. The independent variables were the groups: women who have carried at least one pregnancy to viability ( $\geq 1$ para) and women who have never given birth (nullipara). The covariates were the age and the level of education. 


\section{Results}

\subsection{Cognitive Performance}

Accuracy rate (Figure 3a) was $51.61 \pm 14.09 \%$ in the parous group and $53.04 \pm 14.21 \%$ in the nulliparous group, while reaction time (Figure $3 \mathrm{~b}$ ) was $831.97 \pm 207.21 \mathrm{~ms}$ in the parous group and $924.43 \pm 248.71 \mathrm{~ms}$ in the nulliparous group. MANCOVA revealed no significant between-group differences in terms of accuracy rates and reaction times $(p>0.05)$.

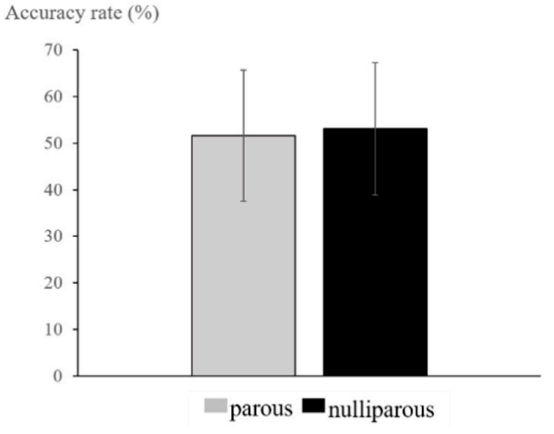

(a)

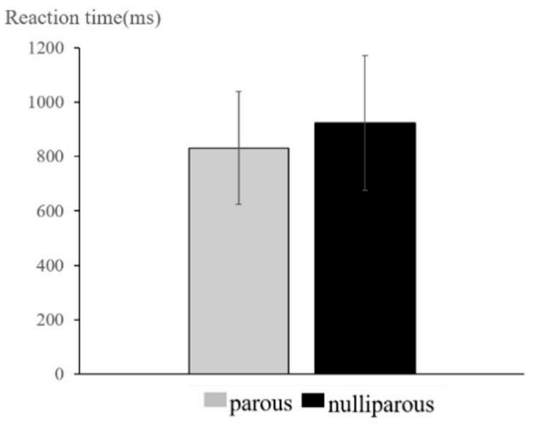

(b)

Figure 3. The 3-back task. (a) Accuracy rate and (b) reaction time.

\subsection{ERP Analysis}

Figure 4 shows the average ERP pattern at $\mathrm{Fz}, \mathrm{Cz}$, and Pz channels by group. N100, P300, and P600 were observed across all channels. MANCOVA results showed that there were no significant differences in amplitude for any of the components (N100, P300, P600, P300p_p, P600p_p) between the two groups $(p>0.05)$.

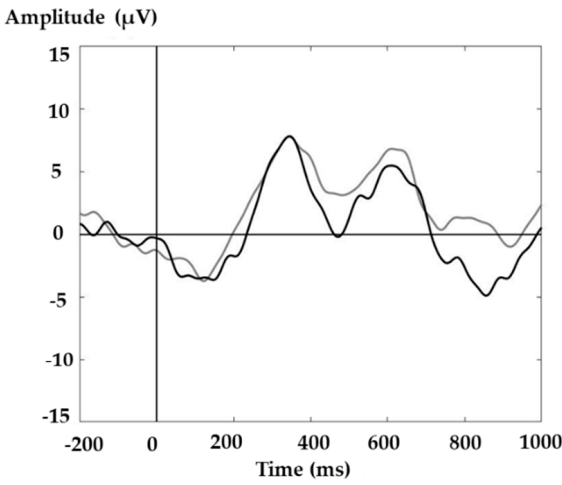

(a)

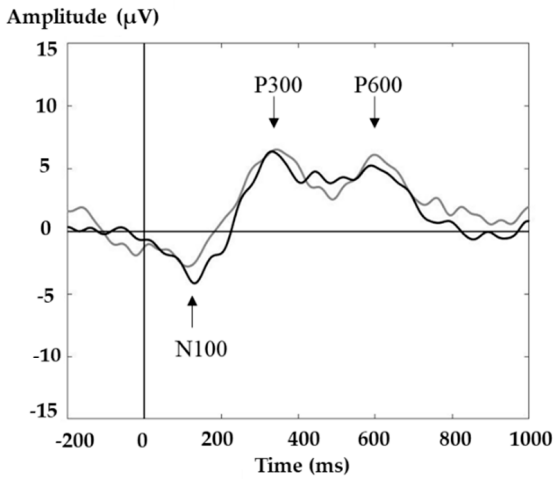

(b)

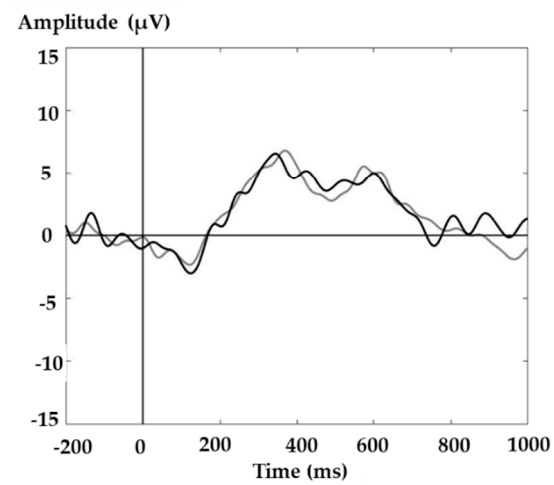

- parous

- nulliparous

(c)

Figure 4. The grand average event-related potential (ERP) pattern at each channel: (a) $\mathrm{Fz},(\mathbf{b}) \mathrm{Cz}$, and (c) Pz. 


\section{Discussion}

In this study, we evaluated the cognitive differences between parous and nulliparous females using the 3-back task and analyzed EEG data for electrophysiology. There were no differences between the two groups in terms of the correct answer rate or response time. In addition, there were no significant differences in terms of amplitude values of the N100, P300, P600, P300p_p, or P600p_p components at Fz, Cz, and Pz.

To date, there have been no conclusive reports regarding the correlation between pregnancy/birth and cognitive abilities, i.e., whether pregnancy affects cognitive function and whether the effect persists after birth. In a previous study, women in their second trimester (13-26 weeks) tended to rate themselves as more cognitively impaired than before compared to nulliparous women, but the two groups did not differ in their performance on objective cognitive function tests [1].

Changes in memory are known to be primarily caused by complex hormonal changes during pregnancy, birth, or the postpartum period [3]. Oxytocin, which plays an integral part in labor by inducing powerful contractions of the uterus, is known to affect memory and cognitive performance, but no correlation between pregnancy-associated increases in oxytocin levels and changes in cognitive abilities has been found [8]. In addition, estradiol, which is a steroid hormone that is produced during the estrous cycle (the preparatory stage for mating), is known to be maintained at levels proportional to the concentration of hippocampal apical dendritic spines in adult human females. Increased concentrations indicate increased synaptic surface area, which may enhance learning and memory $[4,5]$. In a similar animal study, estradiol was injected into ovariectomized female rats, which affected dorsal hippocampal formation (which orchestrates spatial and episodic memories), leading to improvements in memory consolidation [9].

As pregnancy progresses, cortisol levels, which are associated with impairments in hippocampus-dependent cognitive domains such as language and visuospatial memories, rapidly increase. Continued exposure to high levels of cortisol has been shown to impair emotional and cognitive functions like the processing of selective attention and visual components, with associated low scores in most neuropsychological tests compared to normal controls $[7,10]$. Similarly, women in their third trimester of pregnancy who have high levels of estradiol and cortisol have significantly lower mean levels of performance on a verbal recall memory task compared to nonpregnant women. However, no significant difference has been found in working memory task performance $[6,11,12]$. Therefore, while hormonal changes during pregnancy and the postpartum period can induce cognitive impairments and neuropsychiatric disorders like postpartum depression, consistent results have not been obtained [13].

Almost no studies have investigated cognitive performance depending on pregnancy and parity status in terms of brain function using ERP. In this study, we used a working memory task to compare parity-dependent levels of cognitive performance. The amplitude of the N100 component, which is the ERP observed during working memory tasks, generally changes depending on the attention being allocated [39]. The P300 component reflects activation of the event-categorization network for attention, judgment, recall, and working memory [21,22]. In particular, P300 amplitude is directly related to memory, and it reacts sensitively to the activation of attention resources during task execution [40-42]. Moreover, the P300 amplitude represents the degree of activation of the central nervous system associated with the incoming information processing [43]. The P600 amplitude is sensitive to mild cognitive impairment (memory impairment) and thus provides an objective measurement of memory dysfunction. It has also been reported to be closely related to memory load, memory maintenance, and attention [23,44-47].

In this study, we recorded ERPs during a working memory task known as the 3back task at the $\mathrm{Fz}, \mathrm{Cz}$, and $\mathrm{Pz}$ sites, which are part of the neural circuit that connects the prefrontal cortex and inferior parietal cortex and is highly associated with working memory [21,25,48-51]. The ERP components N100, P300, and P600, which are highly correlated with attention allocation, focused attention, judgment, memory, and recall were then 
analyzed. We found no significant between-group differences in either the ERP amplitudes or task performance (percent correct, reaction time).

In order to understand the effect of pregnancy on cognitive function, we attempted to objectively prove whether a decrease in cognitive performance actually occurred in women after childbirth by using a working memory task (3-back task). If pregnancy and childbirth had a negative effect on cognitive function, the experimental results would have reflected a negative effect in the group of women who have had experienced childbirth. However, this study demonstrated that there is no difference in the objective cognitive function between women who had given birth and women who had not given birth through the 3-back task, which is in contrast to the worries of women that "there would be a loss of cognitive function due to childbirth". Cognitive function is a crucial factor in the process of giving birth in a safe place, nurturing children, and continuing the preservation of the race. Although this study did not demonstrate a positive effect between the results of childbirth, cognitive performance (3-back task), and the ERP pattern, it presented a significant result that childbirth does not have a negative effect on the decline of women's working memory among the cognitive functions, through objective data. Although the present study did not obtain hormonal data, which have been used in most previous studies, we believe examining ERP patterns in the brain, another objective biosignal, can be used effectively to associate neural responses with actual behavioral output.

In conclusion, this study revealed no significant differences in behavioral or electrophysiological results between the parous and nulliparous groups. These results suggest that giving birth does not significantly impact cognitive function. However, there were some limitations to this study. First, the number of subjects participating in this study was low, and the influence of some hormones may have been lower since the parous group was composed of participants who had given birth within the previous three years and were not tested immediately after childbirth. Second, the only cognitive task conducted in this study was the 3-back task. We intend to recruit a variety of childbirth groups with an increased number of participants in the future by considering the quantitative control over the period after childbirth (comparison of groups within three years of childbirth and three or more years after childbirth, as well as comparison between groups by each year after childbirth), the delivery method, and the number of births. In addition, more in-depth studies should be conducted regarding the effect of childbirth on cognitive performance through the use of various cognitive tasks.

From the analytical perspective, studies must be conducted by classifying the signal using independent component analysis, performing a correlation analysis between cognitive measures and ERP amplitude/latency, and using various analysis methods such as nonparametric statistical tests as well as adaptive mean amplitude extraction of ERP patterns to extract the results and compare the ERP patterns according to childbirth.

Author Contributions: Conceptualization, M.-H.C. and H.-J.K.; methodology, M.-H.C., H.-J.K., and S.-C.C.; formal analysis, M.-H.C., J.-J.J., and J.-H.L.; investigation, H.-K.P., J.-J.J., and H.-J.K.; resources, H.-K.P., H.-J.K., and S.-C.C.; data curation, M.-H.C., J.-J.J., and S.-C.C.; writing-original draft preparation, M.-H.C., S.-C.C., and H.-J.K.; writing-review and editing, M.-H.C., S.-C.C., and H.-J.K.; visualization, M.-H.C. and H.-J.K.; project administration, H.-J.K.; funding acquisition, H.-J.K. All authors have read and agreed to the published version of the manuscript.

Funding: This research was supported by Basic Science Research Program through the National Research Foundation of Korea (NRF) funded by the Ministry of Education (NRF-2017R1D1A3B04031900).

Institutional Review Board Statement: This study was approved by the Institutional Bioethics Committee of Konkuk University (IRB project number: 7001355-201709-HR-203) and complied with the regulations of the Helsinki Declaration.

Informed Consent Statement: Not applicable.

Data Availability Statement: The datasets generated for this study are available on request to the corresponding author. 
Conflicts of Interest: The authors declare no conflict of interest.

\section{References}

1. Crawley, R.A.; Dennison, K.; Carter, C. Cognition in pregnancy and the first year post-partum. Psychol. Psychother. 2003, 76, 69-84. [CrossRef] [PubMed]

2. Parsons, C.; Redman, S. Self-reported cognitive change during pregnancy. Aust. J. Adv. Nurs. Q. Publ. R. Aust. Nurs. Fed. 1991, 9, 20-29.

3. Brett, M.; Baxendale, S. Motherhood and memory: A review. Psychoneuroendocrinology 2001, 26, 339-362. [CrossRef]

4. Daniel, J.M.; Roberts, S.L.; Dohanich, G.P. Effects of ovarian hormones and environment on radial maze and water maze performance of female rats. Physiol. Behav. 1999, 66, 11-20. [CrossRef]

5. Kinsley, C.H.; Madonia, L.; Gifford, G.W.; Tureski, K.; Griffin, G.R.; Lowry, C.; Williams, J.; Collins, J.; Mclearie, H.; Lambert, K.G. Motherhood improves learning and memory. Nature 1999, 402, 137-138. [CrossRef]

6. Glynn, L.M. Giving birth to a new brain: Hormone exposures of pregnancy influence human memory. Psychoneuroendocrinology 2010, 35, 1148-1155. [CrossRef]

7. Forget, H.; Lacroix, A.; Somma, M.; Cohen, H. Cognitive decline in patients with Cushing's syndrome. J. Int. Neuropsychol. Soc. 2000, 6, 20-29. [CrossRef]

8. Silber, M.; Almkvist, O.; Larsson, B.; Uvnäs-Moberg, K. Temporary peripartal impairment in memory and attention and its possible relation to oxytocin concentration. Life Sci. 1990, 47, 57-65. [CrossRef]

9. Spencer, J.L.; Waters, E.M.; Romeo, R.D.; Wood, G.E.; Milner, T.A.; Mcewen, B.S. Uncovering the mechanisms of estrogen effects on hippocampal function. Front. Neuroendocr. 2008, 29, 219-237. [CrossRef]

10. Hinkelmann, K.; Moritz, S.; Botzenhardt, J.; Riedesel, K.; Wiedemann, K.; Kellner, M.; Otte, C. Cognitive impairment in major depression: Association with salivary cortisol. Biol. Psychiatry 2009, 66, 879-885. [CrossRef]

11. Glynn, L.M.; Schetter, C.D.; Chicz-Demet, A.; Hobel, C.J.; Sandman, C.A. Ethnic differences in adrenocorticotropic hormone, cortisol and corticotropin-releasing hormone during pregnancy. Peptides 2007, 28, 1155-1161. [CrossRef] [PubMed]

12. Tulchinsky, D.; Hobel, C.J.; Yeager, E.; Marshall, J.R. Plasma estrone, estradiol, estriol, progesterone, and 17-hydroxyprogesterone in human pregnancy: I. Normal pregnancy. Am. J. Obs. Gynecol. 1972, 112, 1095-1100. [CrossRef]

13. Workman, J.L.; Barha, C.K.; Galea, L.A. Endocrine substrates of cognitive and affective changes during pregnancy and postpartum. Behav. Neurosci. 2012, 126, 54. [CrossRef]

14. Maggi, A.; Susanna, L.; Bettini, E.; Mantero, G.; Zucchi, I. Hippocampus: A Target for Estrogen Action in Mammalian Brain. Mol. Endocrinol. 1989, 3, 1165-1170. [CrossRef]

15. Henry, J.D.; Rendell, P.G. A review of the impact of pregnancy on memory function. J. Clin. Exp. Neuropsyc. 2007, $29,793-803$. [CrossRef]

16. Christensen, H.; Leach, L.S.; Mackinnon, A. Cognition in pregnancy and motherhood: Prospective cohort study. Br. J. Psychiatry 2010, 196, 126-132. [CrossRef] [PubMed]

17. Keenan, P.A.; Yaldoo, D.T.; Stress, M.E.; Fuerst, D.R.; Ginsburg, K.A. Explicit memory in pregnant women. Am. J. Obs. Gynecol. 1998, 179, 731-737. [CrossRef]

18. Sharp, K.; Brindle, P.M.; Brown, M.W.; Turner, G.M. Memory loss during pregnancy. BJOG 1993, 100, 209-215. [CrossRef] [PubMed]

19. Janes, C.; Casey, P.; Huntsdale, C.; Angus, G. Memory in pregnancy. I: Subjective experiences and objective assessment of implicit, explicit and working memory in primigravid and primiparous women. J. Psychosom. Obs. Gynecol. 1999, 20, 80-87. [CrossRef] [PubMed]

20. Suzuki, S.; Dennerstein, L.; Armstrong, S.M.; Satohisa, E. Sleeping patterns during pregnancy in Japanese women. J. Psychosom. Obs. Gynecol. 1994, 15, 19-26. [CrossRef]

21. Kim, M.S.; Kwon, J.S.; Kim, J.J. The neurophysiological mechanism of working memory: An event-related potential study. Korean J. Psychol. 2004, 23, 313-326.

22. Kok, A. On the utility of P3 amplitude as a measure of processing capacity. Psychophysiology 2001, 38, 557-577. [CrossRef]

23. Olichney, J.M.; Taylor, J.R.; Gatherwright, J.; Salmon, D.P.; Bressler, A.J.; Kutas, M.; Iragui-Madoz, V.J. Patients with MCI and N400 or P600 abnormalities are at very high risk for conversion to dementia. Neurology 2008, 70, 1763-1770. [CrossRef] [PubMed]

24. Onton, J.; Delorme, A.; Makeig, S. Frontal midline EEG dynamics during working memory. Neuroimage 2005, 27, 341-356. [CrossRef] [PubMed]

25. Perfetti, B.; Varanese, S.; Mancino, E.; Mercuri, P.; Tesse, M.; Franciotti, R.; Onofrj, M. Electrophysiological indices of interference resolution covary with individual fluid intelligence: Investigating reactive control processes in a 3-back working memory task. NeuroImage 2014, 93, 146-153. [CrossRef] [PubMed]

26. Callicott, J.H.; Ramsey, N.F.; Tallent, K.; Bertolino, A.; Knable, M.B.; Coppola, R.; Weinberger, D.R. Functional magnetic resonance imaging brain mapping in psychiatry: Methodological issues illustrated in a study of working memory in schizophrenia. Neuropsychopharmacology 1998, 18, 186-196. [CrossRef]

27. Bosch, V.; Mecklinger, A.; Friederici, A.D. Slow cortical potentials during retention of object, spatial, and verbal information. Cogn. Brain Res. 2001, 10, 219-237. [CrossRef] 
28. Mecklinger, A.; Pfeifer, E. Event-related potentials reveal topographical and temporal distinct neuronal activation patterns for spatial and object working memory. Cogn. Brain Res. 1996, 4, 211-224. [CrossRef]

29. Donchin, E.; Coles, M.G. Is the P300 component a manifestation of context updating. Behav. Brain Sci. 1988, 11, 357-427. [CrossRef]

30. Gevins, A.; Smith, M.E.; McEvoy, L.; Yu, D. High-resolution EEG mapping of cortical activation related to working memory: Effects of task difficulty, type of processing, and practice. Cereb. Cortex 1997, 7, 374-385. [CrossRef]

31. Kim, S.; Liu, Z.; Glizer, D.; Tannock, R.; Woltering, S. Adult ADHD and working memory: Neural evidence of impaired encoding. Clin. Neurophysiol. 2014, 125, 1596-1603. [CrossRef]

32. Kutas, M.; Hillyard, S.A. Event-related brain potentials to semantically inappropriate and surprisingly large words. Biol. Psychol. 1980, 11, 99-116. [CrossRef]

33. Osterhout, L.; Holcomb, P.J. Event-related brain potentials elicited by syntactic anomaly. J. Mem. Lang. 1992, 31, 785-806. [CrossRef]

34. Wilson, G.F.; Swain, R.A.; Davis, I. Topographical analysis of cortical evoked activity during a variable demand spatial processing task. Aviat. Space Environ. Medicat. 1994, 65, 54-61.

35. Osterhout, L.; Holcomb, P.J. Event-related potentials and language comprehension. Oxf. Univ. Press 1995, 171-215.

36. Dong, S.; Reder, L.M.; Yao, Y.; Liu, Y.; Chen, F. Individual differences in working memory capacity are reflected in different ERP and EEG patterns to task difficulty. Brain Res. 2015, 1616, 146-156. [CrossRef] [PubMed]

37. Sokhadze, E.M.; Casanova, M.F.; Casanova, E.L.; Lamina, E.; Kelly, D.P.; Khachidze, I. Event-related potentials (ERP) in cognitive neuroscience research and applications. NeuroRegulation 2017, 4, 14. [CrossRef]

38. Salthouse, T.; Babcock, R.L. Decomposing adult age differences in working memory. Dev. Psychol. 1991, 27, 763. [CrossRef]

39. Hillyard, S.A.; Hink, R.F.; Schwent, V.L.; Picton, T.W. Electrical signs of selective attention in the human brain. Science 1973, 182, 177-180. [CrossRef]

40. Polich, J. Clinical application of the P300 event-related brain potential. Phys. Med. Rehabil. Clin. 2004, 15, 133-161. [CrossRef]

41. Fabiani, M.; Karis, D.; Donchin, E. Effects of mnemonic strategy manipulation in a Von Restorff paradigm. Electroencephalogr. Clin. Neurophysiol. 1990, 75, 22-35. [CrossRef]

42. Johnson, R. Event-related potential insights into the neurobiology of memory systems. In Handbook of Neuropsychology; Boller, F., Grafman, J., Eds.; Elsevier: Amsterdam, The Netherlands, 1995; Volume 10, pp. 135-163.

43. Johnson, R. On the neural generators of the P300 component of the event-related potential. Psychophysiology 1993, 30, 90-97. [CrossRef]

44. Olichney, J.M.; Pak, J.; Salmon, D.P.; Yang, J.; Gahagan, T.; Nowacki, R.; Hansen, L.; Galasko, D.; Kutas, M.; Iragui-Madoz, V.J. Abnormal P600 word repetition effect in elderly persons with preclinical Alzheimer's disease. Cogn. Neurosci. 2013, 4, 143-151. [CrossRef]

45. Paller, K.A.; Kutas, M. Brain potentials during memory retrieval provide neurophysiological support for the distinction between conscious recollection and priming. J. Cogn. Neurosci. 1992, 4, 375-392. [CrossRef]

46. Olichney, J.M.; Morris, S.K.; Ochoa, C.; Salmon, D.P.; Thal, L.J.; Kutas, M.; Iragui, V.J. Abnormal verbal event related potentials in mild cognitive impairment and incipient Alzheimer's disease. J. Neurol. Neurosurg. Psychiatry 2002, 73, 377-384. [CrossRef]

47. Kusak, G.; Grune, K.; Hagendorf, H.; Metz, A. Updating of working memory in a running memory task: An event-related potential study. Int. J. Psychophysiol. 2000, 39, 51-65. [CrossRef]

48. Owen, A.M.; Evans, A.C.; Petrides, M. Evidence for a two-stage model of spatial working memory processing within the lateral frontal cortex: A positron emission tomography study. Cereb. Cortex 1996, 6, 31-38. [CrossRef]

49. Macleod, A.K.; Buckner, R.L.; Miezin, F.M.; Petersen, S.E.; Raichle, M.E. Right anterior prefrontal cortex activation during semantic monitoring and working memory. NeuroImage 1998, 7, 41-48. [CrossRef]

50. Nystrom, L.E.; Braver, T.S.; Sabb, F.W.; Delgado, M.R.; Noll, D.C.; Cohen, J.D. Working memory for letters, shapes, and locations: fMRI evidence against stimulus-based regional organization in human prefrontal cortex. NeuroImage 2000, 11, 424-446. [CrossRef] [PubMed]

51. Weinberger, D.R.; Mattay, V.; Callicott, J.; Kotrla, K.; Santha, A.; Van Gelderen, P.; Duyn, J.; Moonen, C.; Frank, J. fMRI applications in schizophrenia research. NeuroImage 1996, 4, S118-S126. [CrossRef] [PubMed] 